\title{
Evaluation of Heat Stress, Heat Strain, and Rhabdomyolysis during Structural Fire
}

Fighter Training

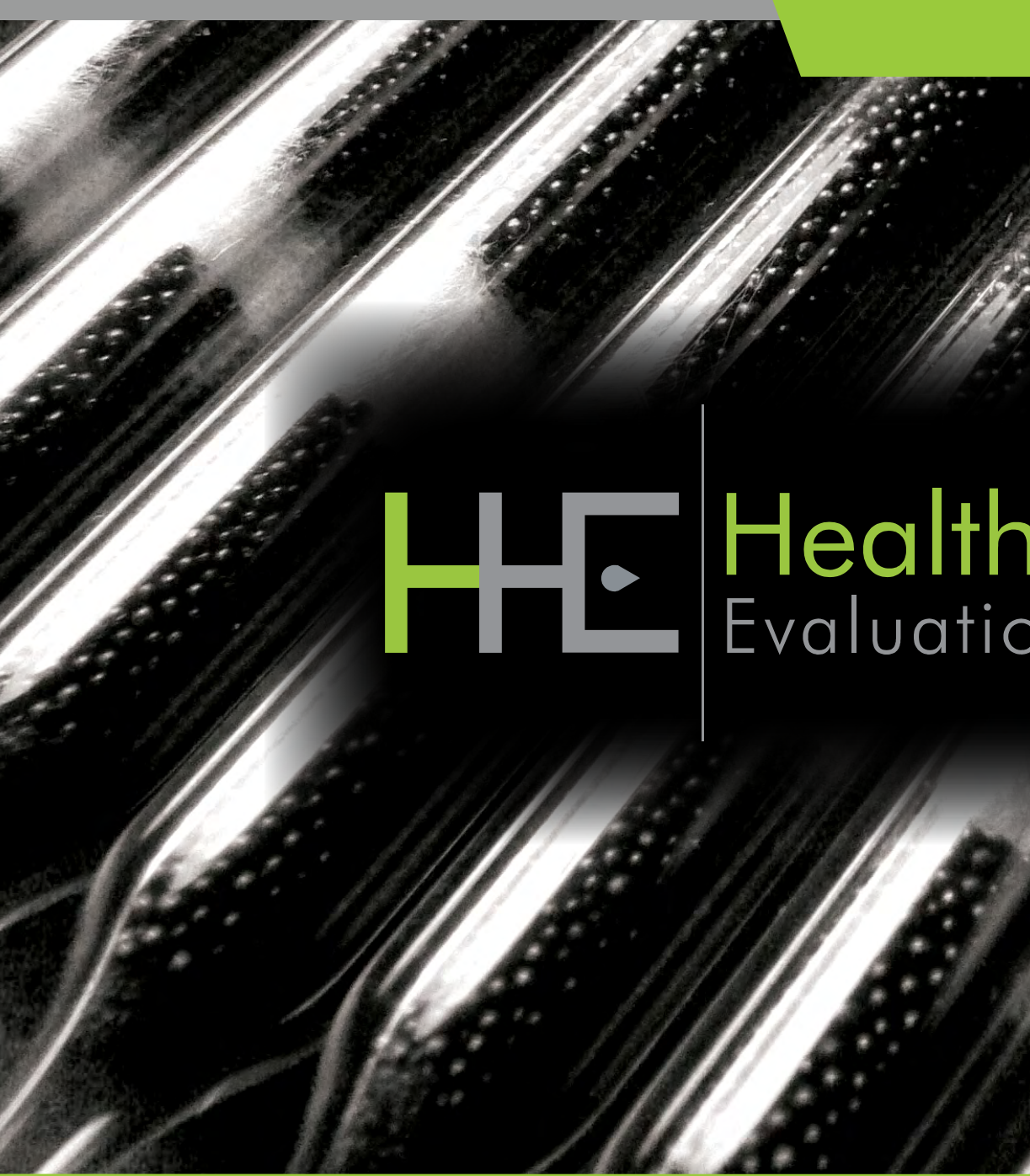

Report No. 2012-0039-3242

September 2015

Judith Eisenberg, MD, MS Mark Methner, PhD, CIH Chad H. Dowell, MS, CIH Charles Mueller, MS

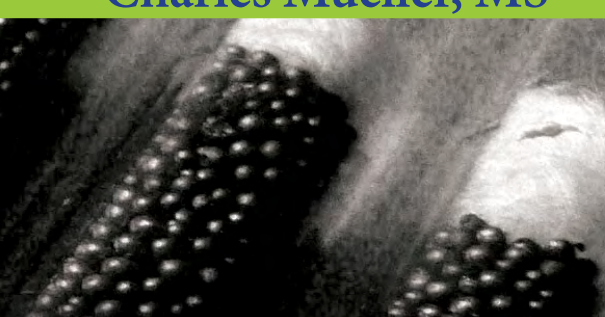




\section{Contents}

Highlights.

Abbreviations ...................................... iii

Introduction ............................................ 1

Methods ............................................. 2

Results ............................................... 6

Discussion ........................................ 12

Conclusions ...................................... 13

Recommendations.......................... 14

Appendix A ....................................... 15

Appendix B ......................................... 17

Appendix C ........................................... 18

Appendix D .................................... 22

References..................................... 23

Acknowledgements............................ 27

The employer is required to post a copy of this report for 30 days at or near the workplace(s) of affected employees. The employer must take steps to ensure that the posted report is not altered, defaced, or covered by other material.

The cover photo is a close-up image of sorbent tubes, which are used by the HHE Program to measure airborne exposures. This photo is an artistic representation that may not be related to this Health Hazard Evaluation. Photo by NIOSH. 


\section{Highlights of this Evaluation}

The Health Hazard Evaluation Program received a request from a fire department to evaluate the risk of heat related illness and rhabdomyolysis to cadets and instructors during training. Rhabdomyolysis is the breakdown of muscle tissue.

\section{What We Did}

- We conducted a 4-day evaluation in August 2012 during week 8 of a 10-week training course.

- We asked 32 participants to complete a questionnaire about their work history, medical history, and health symptoms.

- We measured core body temperature and heart rate in 22 participants.

- We analyzed participants' blood for markers of muscle breakdown (creatine kinase) and dehydration during and after the 8 th week of the training course.

- We asked participants at the end of each workday how much fluid they drank. We also asked if they had symptoms of heat-related illness and muscle breakdown.

- We measured body weight before and after each training day.

- We measured environmental conditions each day.

- We had group discussions with participants about their knowledge of rhabdomyolysis.

\section{What We Found}

We evaluated cadets and instructors for heat stress, heat strain, and muscle breakdown during fire fighter training. Environmental conditions, core body temperatures, and heart rates often exceeded guidelines during strenuous activities. We identified one individual with rhabdomyolysis. We recommend scheduling strenuous training during cooler parts of the day/year and educating fire fighters on heat-related illnesses and rhabdomyolysis.

- One participant had rhabdomyolysis.

- Sixteen participants had a creatine kinase level in their blood that was elevated but below the level we considered as rhabdomyolysis. This means that muscle breakdown was occurring but not enough to require medical treatment.

- Most participants met our criteria for excessive heat strain at some point during the testing week.

- Environmental conditions often exceeded heat stress limits.

- Educational materials about the signs, symptoms, and risk of rhabdomyolysis specific for structural fire fighters are needed. 


\section{What the Employer Can Do}

- Conduct physically demanding activities during cooler parts of the day.

- Schedule training courses during cooler months.

- Educate all fire fighters about the signs, symptoms, and dangers of heat-related illness and rhabdomyolysis.

\section{What Employees Can Do}

- Learn the signs and symptoms of excessive heat strain and rhabdomyolysis.

- Tell your supervisor immediately if you have symptoms of heat-related illness or rhabdomyolysis or if you see these symptoms in other fire fighters.

- Drink plenty of fluids, and take rest breaks as needed.

- Talk to your healthcare provider about your job and your increased risk for rhabdomyolysis. 


\section{Abbreviations}

$\begin{array}{ll}\text { ACGIH® } & \text { American Conference of Governmental Industrial Hygienists } \\ \text { bpm } & \text { Beats per minute } \\ \text { BUN } & \text { Blood urea nitrogen } \\ \text { CBT } & \text { Core body temperature } \\ \text { CFR } & \text { Code of Federal Regulations } \\ \text { CK } & \text { Creatine kinase } \\ \text { F } & \text { Fahrenheit } \\ \text { HRI } & \text { Heat-related illness } \\ \text { IU/L } & \text { International units per liter } \\ \text { mOsm/L } & \text { Milliosmoles per liter } \\ \text { NIOSH } & \text { National Institute for Occupational Safety and Health } \\ \text { OSHA } & \text { Occupational Safety and Health Administration } \\ \text { TLV® } & \text { Threshold limit value } \\ \text { WBGT } & \text { Wet bulb globe temperature }\end{array}$


This page left intentionally blank 


\section{Introduction}

The Health Hazard Evaluation Program received a request from a fire department about the potential for rhabdomyolysis and heat-related illness (HRI) in cadets and instructors participating in training classes. At the time of the evaluation, the cadet training course consisted of classroom lectures in an air-conditioned environment and outdoor activities that included physical training and live fire suppression exercises in full protective gear. We conducted our on-site evaluation in August 2012.

Training was conducted Monday through Thursday, with Friday through Sunday designated as rest days. In addition to classroom lectures, outdoor activities consisted of physical training (e.g., running, calisthenics) and a 1-day live fire suppression exercise inside a sixstory building. During the live fire exercise, two cadets were paired with an instructor while fighting a fire inside the building. A camera monitored personnel inside the building. Once an entry team ( 2 cadets and an instructor) left the live fire building, they recovered in a shaded area equipped with fan-driven, water misting coolers and cold drinking water. On days without live fire training, activities included set-up, inspection, and wearing of personal protective equipment; fire hose handling; climbing ladders; and maneuvering up and down high rise building stairs. Cadets had access to air conditioned trailers during their lunch break. We considered all participants acclimatized because this evaluation was conducted during the eighth week of the 10-week training course under consistent environmental conditions.

\section{Heat-Related IIIness and Rhabdomyolysis}

Heat exposure resulting in elevated core body temperatures and prolonged, intense exertion are risk factors for rhabdomyolysis, but they are also, unfortunately, a consequence of fire fighting. Heat stress is the sum of the heat generated in the body (metabolic heat) plus the heat gained from the environment (environmental heat) minus the heat lost from the body to the environment [NIOSH 2013]. Many bodily responses to heat stress are desirable and beneficial; however, at some stage of heat stress, the body cannot maintain an internal temperature required for normal functioning. As a result, the risk of HRI and accidents occurring from impaired mental status increases.

The body's response to heat stress is called heat strain. Heat strain is dependent on a number of factors and cannot be predicted on the basis of environmental heat stress measurements alone. As a result of working in a hot environment, HRI may develop. HRI includes disorders such as:

- Heat stroke - Caused by an excessive rise in body temperature and failure of the temperature regulating mechanism. It is characterized by a change in mental status, which can range from confusion or bizarre behavior to seizures and loss of consciousness. It is often preceded by signs and symptoms of heat exhaustion as described below. Body temperature may be above $106^{\circ} \mathrm{F}$, but there is no specific temperature used to make the diagnosis. Heat stroke is a medical emergency and can be fatal if not immediately treated. 
- Heat exhaustion - Characterized by muscular weakness, distress, nausea, vomiting, dizziness, pale clammy skin, and fainting. It is usually associated with lack of heat acclimatization and physical fitness, poor health status, and inadequate water intake.

- Heat rash - Skin irritation that occurs most often in hot environments and causes skin to become red and itchy. The rash usually appears in areas where clothing is restrictive.

- Heat cramps - Muscle pains or spasms that can happen during prolonged work or exercise in high temperatures.

Rhabdomyolysis, or muscle tissue breakdown, is the result of any process that causes injury to or death of muscle tissue. Muscle tissue can be damaged by overheating, overexertion, crush injury, some medications or supplements, or certain medical conditions. When muscle cells die, their contents of electrolytes and proteins are released into the bloodstream, which can result in potentially life-threatening conditions affecting the heart and kidneys [Khan 2009]. The association between heat stroke and rhabdomyolysis is well known [Department of the Army and Air Force 2003; Bontempo and Kaji 2010; O'Connor and Duester 2011; ACGIH 2015]. Rhabdomyolysis and acute kidney failure often occur together in people with exertional heat stroke [Bontempo and Kaji 2010]. Rhabdomyolysis is serious; up to $8 \%$ of documented rhabdomyolysis cases are fatal [Cervellin et al. 2010]. Rhabdomyolysis can also result in permanent disability. More information about heat stress, heat strain, and rhabdomyolysis is in Appendix C.

\section{Methods}

The objectives of this evaluation were to determine if cadets participating in the training class had:

- Excessive heat strain

- Signs and symptoms of HRI, or rhabdomyolysis

- Personal and work-related risk factors for excessive heat strain, HRI, or rhabdomyolysis

- Evidence of dehydration

We evaluated 30 of 32 cadets and the 2 primary course instructors during week 8 of a 10 -week training course. On the first day of our evaluation, we obtained informed consent from the cadets and instructors, and ensured they had no medical reasons that would exclude them from participating, such as digestive problems, having a pacemaker, or pregnancy. Our evaluation methods included:

- Administering a one-time questionnaire about work and medical history

- Questioning participants daily about symptoms

- Testing participants' blood before and after each training day and twice a day on rest days for markers of rhabdomyolysis and dehydration until results showed two successively declining CK levels or the HHE ended

- Measuring participants' core body temperature (CBT), exertion, and heart rate during training days 
- Measuring participants' body weight before and after each training day

- Assessing environmental conditions on training days

- Observing training activities to estimate workload

- Conducting a focus group about cadets' knowledge of rhabdomyolysis

\section{Questionnaire}

On the first day of the evaluation we asked each participant to complete a questionnaire on work and medical history, including risk factors for and previous diagnoses of rhabdomyolysis or HRI. We asked about recent use (past 2 weeks) of medications, supplements, and beverages that could increase the risk for rhabdomyolysis or HRI. We also asked about possible rhabdomyolysis and HRI signs and symptoms experienced since starting the training course 8 weeks earlier.

\section{Postshift Symptom Surveys}

At the end of their shift during training days (Monday through Thursday) and on their first rest day (Friday) following training, we asked participants if they had symptoms that could be associated with rhabdomyolysis or HRI. We asked if they had unusual soreness in the arms, legs, or back after completing that day's training, if they felt rested or recovered prior to starting training that day, and if they had noted darker than normal urine on that day. We also asked them to estimate their total fluid intake during training that day.

\section{Blood Analysis for Markers of Rhabdomyolysis and Dehydration}

We collected blood samples before and after each training day and twice a day on rest days. Approximately three to six drops of whole blood were collected via fingerstick and analyzed using the Abaxis Piccolo ${ }^{\circledR}$ Metlyte 8 Reagent Disc in a Piccolo Xpress ${ }^{\mathrm{TM}}$ Analyzer. To identify rhabdomyolysis, we measured the amount of creatine kinase (CK), an enzyme that serves as a marker for muscle breakdown. We used a standard definition of rhabdomyolysis as a CK level five times the upper limit of the reference range of the assay [O'Connor and Duester 2011]. We used the following values to identify rhabdomyolysis: $>1,900$ international units/liter (IU/L) for males, and $950 \mathrm{IU} / \mathrm{L}$ for females. The normal reference CK ranges for this assay were 39-380 IU/L for males and 30-190 IU/L for females [Abaxis 2011]. We categorized participants as having an elevated CK but not rhabdomyolysis if their CK was above the upper limit of normal for their sex but below the rhabdomyolysis threshold level. We stopped testing participants when results showed two successively declining $\mathrm{CK}$ levels on rest days. If CK values met or exceeded our case definition levels, we instructed the participant to seek immediate medical attention. We advised participants whose $\mathrm{CK}$ values did not demonstrate two successively declining levels before the end of our testing to follow-up with their healthcare provider within 1 week. 
We measured blood urea nitrogen (BUN) to creatinine ratios and calculated serum osmolarity to determine the level of dehydration. The formula for calculated serum osmolarity [Kelen et al. 2011] is as follows:

Serum Osmolarity $(\mathrm{mOsm} / \mathrm{L})=2 \times[$ serum sodium $]+[$ serum glucose $] / 18+[$ serum BUN $] / 2.8$

We defined dehydration as either a BUN to creatinine ratio higher than 20:1 or a calculated serum osmolarity higher than 290 milliosmoles/liter (mOsm/L) [Singer and Brenner 2008]. When collecting blood samples, we followed the standard precautions for prevention of exposure to bloodborne pathogens as specified by the Centers for Disease Control and Prevention and the Occupational Safety and Health Administration (OSHA) [CDC 1998; 29 CFR 1910.1000]. All blood test results were available within 30 minutes of collection. Any participant with a clinically significant, abnormal test result was contacted immediately. At the end of the week, all participants received a letter containing the results of all their blood tests.

\section{Heat Strain Assessment}

We classified participants as having excessive heat strain if they had one or more of the following:

- A CBT higher than $101.3^{\circ}$ Fahrenheit (F). This definition is in accordance with the American Conference of Governmental Industrial Hygienists (ACGIH) threshold limit value (TLV) heat stress guidelines for acclimatized individuals [ACGIH 2015].

- A heart rate above 180 beats per minute (bpm) minus the age of the participant sustained for at least 3 minutes [ACGIH 2015].

- A body weight loss over a training day greater than 1.5\% [ACGIH 2015].

It should be noted that the 1986 National Institute for Occupational Safety and Health (NIOSH) heat stress criteria document guidance is being updated [NIOSH 2013].

\section{Core Body Temperature}

Before conducting the evaluation, we screened all participants for medical conditions that would preclude them from safely swallowing a Philips Respironics CBT sensor. The single use CBT sensor is about the size of a multivitamin, is biologically inert, and exits the body with a bowel movement. It measures temperature as it passes through the digestive system and wirelessly transmits the data to an Equivital LifeMonitor WQ02 receiver worn outside the body. Using a CBT sensor is considered the most accurate way to measure internal body temperature [Sawka and Pandolf 2001; McKenzie and Osgood 2004; Byrne and Lim 2007].

Each CBT sensor was set to transmit data every 15 seconds. Participants swallowed a new CBT sensor before starting training each morning. Each employee then drank about 16 ounces of water and ate five to 10 saltine crackers to help move the sensor from the stomach into the small intestine where the most accurate CBT is measured. At the end of each workday, we downloaded and stored the CBT data. Participants were not asked to take the CBT sensor on rest days. With the equipment available we were able to monitor 22 participants for CBT across the 4 training days. The first 22 participants who consented and did not have any disqualifying medical condition were selected for this part of the evaluation. 


\section{Heart Rate}

We used the Equivital LifeMonitor EQ02 physiological monitoring system to measure and store employee heart rate data for 22 participants as noted above. The system was set to transmit heart rate data every 15 seconds during each training day. This system consists of a chest strap containing a sensor that contacts the skin and determines the heart rate. The maximum recordable heart rate for this instrument is $240 \mathrm{bpm}$. All heart rate data were wirelessly transmitted and stored. Participants were not asked to wear the heart rate sensor on rest days.

\section{Body Weight}

We measured each participant's body weight before and after each training day to assess fluid losses using a Seca Travelite ${ }^{\mathrm{TM}}$ Model 803 digital scale. We did not weigh participants on rest days.

\section{Heat Stress}

To measure the environmental conditions that contribute to heat stress, we used a Quest Technologies QUESTemp ${ }^{\circ} 36$ instrument to obtain the wet bulb globe temperature (WBGT) at each activity location and in cooling areas. The WBGT measurements were logged electronically at 1-minute intervals during the entire training day. WBGT measurements were also manually recorded by NIOSH staff on a daily activity log at the start of each training activity. We used the daily activity log to describe each activity, its duration, its estimated average metabolic load (exertion level), and rest breaks. We classified metabolic loads as rest, light, moderate, heavy, and very heavy on the basis of NIOSH and ACGIH heat stress criteria, which are the same [NIOSH 1986; ACGIH 2015]. We grouped activities into approximately 1 -hour periods over each day. We then calculated the maximum WBGT during these activity periods. All participants intermittently wore protective equipment such as flame retardant turnout gear and supplied air respirators. However, because the amount of time each participant wore this protective equipment varied, it was unfeasible to make a WBGT clothing adjustment. Instead, we used the maximum WBGT value measured in the area where a specific activity occurred to estimate the heat stress associated with that activity.

\section{Activity Assessment}

Because prolonged, intense physical activity is a risk factor for rhabdomyolysis, we used a Philips Respironics Actical ${ }^{\mathrm{TM}}$ accelerometer to record activity counts or how often a specific motion was repeated. This system uses software to convert activity counts into each participant's total energy expenditure.

\section{Statistical Methods}

We used SAS Version 9.3 (SAS Institute Inc.) for our statistical analyses. We calculated descriptive statistics including means, ranges, frequencies, and percentages. We used the Spearman correlation coefficient with its associated $\mathrm{P}$ value to evaluate relationships between the average number of caffeinated beverages consumed each day and the maximum $\mathrm{CK}$ for the subject. $P$ values less than 0.05 were considered statistically significant. 


\section{Focus Group}

We asked questions on the general consent form regarding each participant's age and years as a fire fighter. We used the responses to these questions to select six participants with diverse backgrounds. A separate consent form for focus group participation was required because the session was recorded. A NIOSH health communication specialist served as the moderator to guide discussions on the participants' knowledge, experiences, beliefs, and needs [Morgan 1998] related to rhabdomyolysis. Focus group discussion topics included the following:

- How familiar participants were with rhabdomyolysis and its risk factors

- Barriers to seeking treatment for possible rhabdomyolysis symptoms

We also asked the focus group participants for suggestions on how they could alert healthcare providers if they sought medical care for signs and symptoms of rhabdomyolysis. We asked for comments on the usefulness of a wallet-sized identification card containing information on rhabdomyolysis. This card had been developed for wildland fire fighters (Figure 1) [NIOSH 2011].

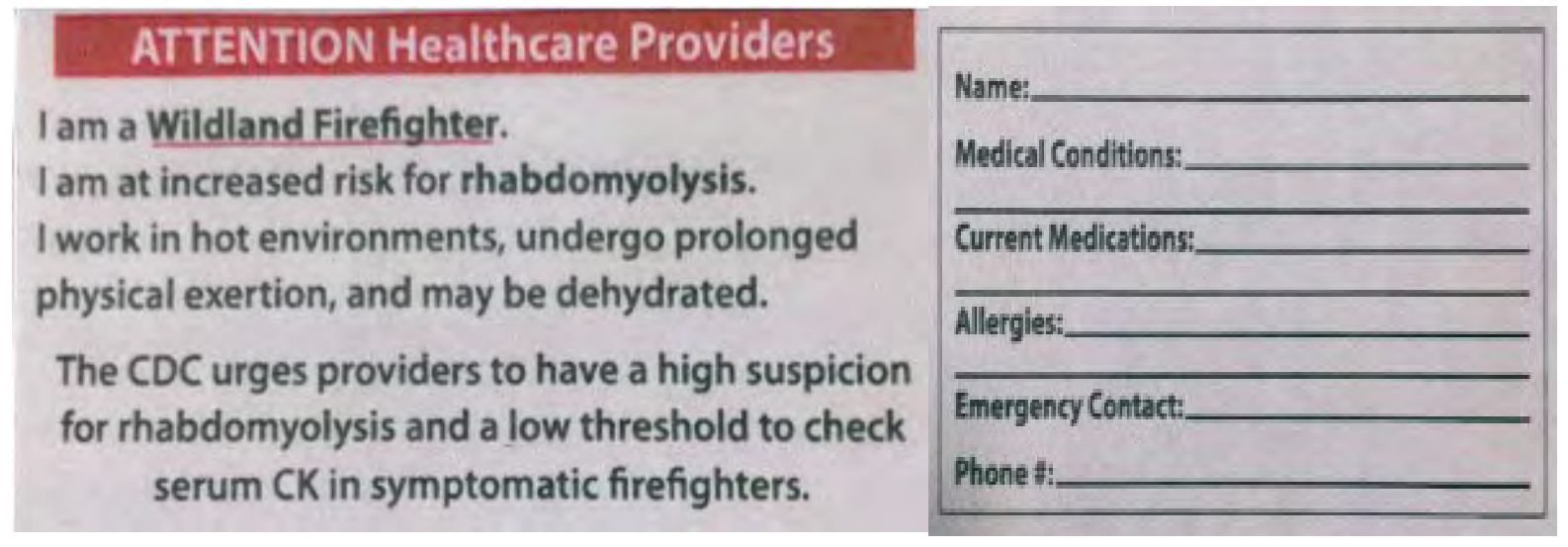

Figure 1. Rhabdomyolysis wallet card developed for wildland fire fighters.

\section{Results}

\section{Questionnaire and Postshift Symptom Survey}

The average age of the 32 participants who completed the questionnaire was 27 (range: 1941) years. All but two were male. Participants reported working as fire fighters for an average of 3 years (range: $0-16$ years). At the time the questionnaire was administered, current medical issues included one report of a heart condition, one report of high cholesterol, two reports of depression and reports of gastritis, allergies, low testosterone, and back/joint pain. One participant answered "yes" to ever being told by a healthcare professional that he/she 
had rhabdomyolysis, decreased kidney function, and "heat stroke, heat strain, or heat stress." Following a discussion with this participant, we learned the participant had a fainting episode due to heat stroke earlier in training and was diagnosed with rhabdomyolysis and decreased kidney function, which subsequently returned to normal.

We asked participants to rate their level of agreement with statements about withdrawing from the training due to illness. The rating scale was $1-5$, with 1 being strongly disagree and 5 being strongly agree. Of the 27 responding participants, 12 (44\%) reported a 4 (agree) or 5 (strongly agree) for the statement "I feel that I could have withdrawn from this training event at any time if I did feel well." Six reported a 3 (neither agree nor disagree), and nine reported a 1 (strongly disagree). Fifty-six percent (15/27) reported a 4 (agree) or 5 (strongly agree) when asked to rate the statement "If I did become sick during this event I would have notified my trainer/supervisor," while seven reported a 3 (neither agree nor disagree), and 5 reported a 1 (strongly disagree) or 2 (disagree).

We found very limited reported use of substances that have been associated with an increased risk of rhabdomyolysis within the 2 weeks prior to our evaluation. Two participants reported taking creatine-containing substances; three reported taking over-the-counter cold, cough, or allergy medicines; and two reported taking ibuprofen for back or joint pain. One participant reported taking oral steroids, and four reported consuming an over-the-counter energy drink. In order to look at caffeine intake, we asked if they drank caffeinated soda, energy drinks, or coffee/tea. Twenty-eight participants $(88 \%)$ reported drinking these caffeinated beverages in the past 2 weeks, with the highest average amount being reported by one participant as one can of soda, one energy drink, and two cups of coffee per day. We found no statistically significant correlation between the average quantity of these drinks consumed and maximum CK level ( $\mathrm{r}=-0.13, P=0.49)$.

The questionnaire also asked about engaging in intense physical exertion activities for recreation such as hiking, biking, or climbing as these type of activities can also result in increases in CK. Nineteen participants (59\%) reported that they did so. When asked how many days since they last engaged in those activities, the responses ranged from 1 to 10 days.

Table 1 summarizes the questionnaire responses regarding symptoms experienced during the first 7 weeks of the training course. Nine participants reported no symptoms, 15 reported four or fewer symptoms while eight participants reported between 6-9 symptoms. No participant reported 10 or more. The most commonly reported symptoms were unusual muscle aches or pain in arms, legs, or lower back (56\%) and decreased urine output (50\%). 
Table 1. Prevalence of symptoms and signs among participants since the start of the training course $(n=32)$

\begin{tabular}{lc}
\hline Symptom or sign & Number of participants (\%) \\
\hline Unusual muscle aches or pains in the arms, legs, lower back & $18(56)$ \\
Decreased urine output & $16(50)$ \\
Numbness or "pins and needles" sensation in arms or legs & $12(38)$ \\
Diarrhea & $12(38)$ \\
Feverish feeling & $12(38)$ \\
Nausea or vomiting & $11(34)$ \\
Unusually dark urine & $7(22)$ \\
Abdominal pain & $5(16)$ \\
Muscle swelling in the arms or legs & $5(16)$ \\
Oral temperature $>100.4^{\circ} \mathrm{F}$ & $3(9)$ \\
Felt like had flu & $3(9)$ \\
\hline
\end{tabular}

On the postshift symptom surveys, unusual soreness of the arms, legs, and back were infrequently reported, with only two of 32 participants reporting such symptoms on any of the 4 training days. We also asked on the postshift symptom surveys if participants felt rested or recovered in the morning. Between 4 and 15 participants responded "no," with 15 on day 4 (the day after the live burn exercise), and 4 on day 5 . The postshift symptom surveys also asked participants to estimate their fluid intake that day. Responses ranged from 1-10 liters with daily averages ranging from 4-5 liters.

\section{Blood Analysis for Markers of Rhabdomyolysis and Dehydration}

We looked at markers in blood for dehydration: plasma osmolarity and the blood urea nitrogen (BUN)-to-creatinine ratio. We defined dehydration to be an osmolarity greater than $290 \mathrm{mOsm} / \mathrm{L}$ or a BUN-to-creatinine ratio greater than 20:1. Although none of the participants had a plasma osmolarity level above $290 \mathrm{mOsm} / \mathrm{L}$ during the 4 days of training, $78 \%$ had a BUN-to-creatinine ratio above 20:1 during our sampling period, which included rest days. Because these are screening tests, it is possible that the elevated BUN-tocreatinine ratios were indicative of medical conditions other than dehydration. We informed all participants of their individual results and the need to follow up with their health care providers if their BUN-to-creatinine ratio results were high.

We expected to see signs of dehydration among participants because of the increased temperatures and considerable perspiration among the participants performing firefighting activities. We hypothesized that levels of both markers of dehydration would be greater in the postshift sample than in the preshift sample. However, we found that levels of both markers decreased from preshift to postshift on each of the training days in most participants, which suggested that this group of firefighters remained appropriately hydrated each day. Despite 
the possible differing interpretations of the findings regarding dehydration markers, we believe it is prudent to routinely focus on adequate hydration of fire fighters.

Maximum individual CK levels for each participant across all days ranged from $189 \mathrm{IU} / \mathrm{L}$ to $12,665 \mathrm{IU} / \mathrm{L}$. Of the 32 participants, 15 participants had normal CK levels throughout the training. Sixteen participants had CK levels above the normal range for their sex but below the cutoff level for rhabdomyolysis, and one participant demonstrated a CK level that was high enough to meet our case definition for rhabdomyolysis.

The participant who met our case definition exceeded the CK criterion on day 6 and as per protocol, was advised to go to the hospital for treatment. This participant had a maximum $\mathrm{CBT}$ of $102.1^{\circ} \mathrm{F}$ on day 4 (final training day) of our evaluation, did not report any personal risk factors for rhabdomyolysis but did describe symptoms consistent with HRI or rhabdomyolysis that occurred during the earlier weeks of the training event on the questionnaire. However, during days 1 through 5 of the evaluation, the participant denied having muscle soreness or dark urine. When contacted by phone on testing day 6 for notification that the second CK test that day met our case definition of rhabdomyolysis, the participant reported still being asymptomatic. As per our evaluation protocol, we asked the participant to go to the hospital for further evaluation and treatment. Hospital records revealed a peak $\mathrm{CK}$ value of $12,665 \mathrm{IU} / \mathrm{L}$ on day 7 . After being discharged from the hospital and being medically cleared, this participant returned to training.

\section{Heat Strain and Heat Stress}

During our evaluation, 28 of 32 participants met our criteria for excessive heat strain at some time during the testing week. Twenty participants lost more than $1.5 \%$ of their body weight during the training day at least once, with the largest number of participants' weight loss occurring on day 1 (Table 2). According to this indicator of dehydration, substantial fluid loss may have been occurring.

Table 2 summarizes the number of participants whose CBT exceeded the ACGIH recommended limit of $101.3^{\circ} \mathrm{F}$ at any time during the 4 days of training [ACGIH 2015]. Maximum CBT values for each participant on each training day ranged from $98.9^{\circ} \mathrm{F}$ to $107.2^{\circ} \mathrm{F}$ (Appendix A, Tables A1-A4). Most participants' CBT exceeded the limit every training day. Over the 4 training days, at least 67 maximum CBT measurements across all participants exceeded the ACGIH heat strain criterion (some CBT and heart rate data were either not transmitted or not stored). The highest maximum recorded CBT of $107.2^{\circ} \mathrm{F}$ occurred on day 3 during the live fire suppression exercise. During this activity, most participants' CBTs also exceeded the criterion. 
Table 2. Participants exceeding heat strain criteria for weight loss, CBT, or heart rate

\begin{tabular}{lc}
\hline Criteria & $\begin{array}{c}\text { Number and percent } \\
\text { of participants who } \\
\text { met criteria at any } \\
\text { time during testing }\end{array}$ \\
\hline$>1.5 \%$ body weight loss & \\
Day $1(n=32)$ & $14(44)$ \\
Day $2(n=32)$ & $5(16)$ \\
Day $3(n=32)$ & $6(19)$ \\
Day $4(n=32)$ & $5(16)$ \\
CBT $>101.3^{\circ} F$ & \\
Day $1(n=22)$ & $20(91)$ \\
Day $2(n=22)$ & $15(68)$ \\
Day $3(n=21) \dagger$ & $17(81)$ \\
Day $4(n=22)$ & $15(68)$ \\
Heart rate $>180$ minus age in years* & \\
Day $1(n=22)$ & $13(59)$ \\
Day $2(n=21) \dagger$ & $13(62)$ \\
Day $3(n=21) \dagger$ & $14(67)$ \\
Day $4(n=18) \dagger$ & $13(72)$ \\
\hline
\end{tabular}

*Heart rate sustained for 3 or more minutes with measures a maximum of 15 seconds apart

†Equipment failed to transmit or store data for some participants

Applying the $1986 \mathrm{NIOSH}$ recommended exposure limit for heat strain (CBT of $100.4^{\circ} \mathrm{F}$ ) would add 11 more CBT measurements for a total of $78 \mathrm{CBTs}$ that exceeded the guideline. Most of the additional exceedances occurred during high rise building training while wearing protective gear. Nonetheless, all of the exceedances were associated with strenuous activities (high metabolic load $>520$ Watts) performed in a hot environment (WBGT $>77.9^{\circ} \mathrm{F}$ ) (Appendix A, Tables A1-A4).

Between 18 and 22 participants wore a heart rate monitor during the 4 days of training. Thirteen participants' heart rate exceeded the ACGIH maximum heart rate guideline at some point on each of the 4 training days (Table 2). Like the CBT exceedances, most heart rate exceedances occurred during strenuous activities such as exercising (physical training), high rise training where participants climbed six flights of stairs while wearing full protective gear, and live fire suppression exercise (Appendix A, Tables A1-A4). The total number of heart rate measurements per person per day ranged from zero to 2,613, indicating that some participants had missing heart rate data, likely due to intermittent loss of contact between the heart rate sensor and the skin.

Our estimates for the metabolic load of each fire training-related activity ranged from 115 Watts to 520 Watts [ACGIH 2015]. We made WBGT measurements at each activity 
location with the exception of inside the building during the live fire suppression exercise. The WBGT measurements ranged from $65^{\circ} \mathrm{F}$ (inside the air-conditioned classroom) to $96^{\circ} \mathrm{F}$ (outdoors, next to the high-rise building used for multistory building search and rescue training). On multiple occasions high metabolic load activities were performed under environmental conditions that exceeded heat stress guidelines (Appendix A, Tables A1-A4; Appendix B, Figure B1).

\section{Activity Assessment}

The activity data we collected using an Actical accelerometer were highly variable and showed no clear pattern between participant total energy expenditure and specific activities. For example, when participants performed strenuous activity (e.g., carrying loads, climbing stairs and ladders, or working with their hands overhead), there was no corresponding increase in the total energy expenditure data recorded by the Actical. We concluded that these discrepancies in the results were likely due to limitations in the Actical software and that the total energy expenditure calculated by the Actical underestimated the activity intensity. Therefore, we did not use these data and relied on our metabolic load estimates for energy expended.

\section{Focus Group}

We provided the six participants with background information about a prior NIOSH evaluation of wildland fire fighters where we had identified cases of rhabdomyolysis. Participants reported that when they became fire fighters, they were given information regarding the risk for extreme heat exposure, HRI, and dehydration, but not rhabdomyolysis. Four participants stated that they had never heard of rhabdomyolysis until this NIOSH evaluation.

The six probes used to guide the focus group discussion can be found in Appendix D. When asked how rhabdomyolysis information should be presented to fire fighters, participants told us that educational materials should include a picture of a structural fire fighter. The focus group participants also mentioned that if video clips were used, they should show fire fighters in full protective gear. Handouts or brochures would likely not be read, as they already receive an abundance of paper materials. A video or an in-person presentation by a fire fighter who had been diagnosed with rhabdomyolysis was believed to be the best way to deliver this information.

Several participants believed that rhabdomyolysis only happened to those who were not physically fit, or who ate poorly. We explained that rhabdomyolysis was not due to poor diets or lack of physical fitness and often occurred in very fit individuals.

Participants noted that educational information should cover what rhabdomyolysis is, signs and symptoms, diagnostic criteria, and the necessity for immediate evaluation and medical treatment to prevent permanent damage. Participants mentioned that materials must clearly state that without proper medical treatment, rhabdomyolysis can cause permanent disability or death. The mention of removal from the fire service due to disability, dialysis, or loss of muscle function was reported to be a motivator to seek proper medical care.

All participants thought separate materials were needed for structural fire fighters and wildland fire fighters. 
We received mixed opinions when we asked participants about the usefulness of a wallet-sized identification card that could alert healthcare providers about work-related rhabdomyolysis risks. Most informed us that they did not discuss their occupation and associated risk factors with their healthcare provider, although they knew they should. Focus group participants thought having more fire fighters, especially ranking officers, educated about rhabdomyolysis and present when seeking care for possible rhabdomyolysis symptoms would not only help ensure appropriate treatment but could help bridge communication barriers with healthcare providers.

\section{Discussion}

Fire fighters are exposed to heat from several sources, including heat generated by the fire, ambient temperature, heat generated by muscles during physical exertion, and heat trapped by turnout gear (e.g., bunker coat and pants, self-contained breathing apparatus, and Nomex ${ }^{\mathrm{TM}}$ hood). Heat loss capacity is also reduced in high humidity environments where evaporative heat loss from sweating is impeded. The weight of the turnout gear and firefighting equipment adds to the physical exertion, which, in turn, increases the overall heat load. Many of these sources of heat exposure cannot be avoided during training, but can be reduced by scheduling training events during cooler months or cooler parts of the day.

During the 4 days of training, we found that at least 28 of 32 participants met or exceeded our criteria for excessive heat strain. Additionally, most participants exceeded the ACGIHrecommended heat stress guidelines for CBT and heart rate [ACGIH 2015]. On the daily post-shift data download, we found that one participant had a peak CBT of $107.2^{\circ} \mathrm{F}$ during that training day. Although no participant required transport to a hospital for evaluation and treatment of HRI during our evaluation, this was an example of a "near-miss" for a HRI incident and shows the need for closer CBT monitoring during training events.

We found that in spite of the hot working conditions and strenuous training regime, most participants remained adequately hydrated during the work shift. However, our analysis of results from day to day showed some evidence of dehydration present before starting the training day despite leaving training the previous day being adequately hydrated. This indicates that additional emphasis on keeping up with fluid intake after the training day ends needs to occur.

Half of the participants in this evaluation had maximum CK levels which indicated that muscle breakdown was occurring, but not to the degree that required medical evaluation. Only one participant had a CK high enough to meet our case definition despite having had no symptoms of muscle aches or pains, or darkened urine during the course of their elevated CK levels. This individual was diagnosed with rhabdomyolysis in the emergency department. It should be noted that asymptomatic rhabdomyolysis (i.e. diagnosis made solely on elevated CK without any subjective symptoms like muscle pain or outward signs like darkened urine) is not uncommon. One study of patients hospitalized for medical conditions that put them at risk for rhabdomyolysis showed that $50 \%$ of those whose CK levels rose high enough to be rhabdomyolysis cases denied any muscle pain and it took up to 4 days for muscle swelling to manifest [Gabow et al. 1982]. This emphasizes the need for prompt evaluation if and when 
symptoms do become evident as the underlying condition could have been underway for a considerable period by the time someone with rhabdomyolysis begins to feel anything is wrong. The risk for permanent injury from rhabdomyolysis increases the longer it takes to get diagnosed and treatment started.

The focus group participants reported that they had not received any information regarding rhabdomyolysis and its work-related risk factors. Participants noted that educational materials should be tailored to structural fire response fire fighters by using actual fire fighters in any graphics on the educational materials. The focus group consensus was that educational materials would be more likely to prompt fire fighters to report and seek immediate medical attention for rhabdomyolysis related symptoms if they clearly spelled out the potentially life-threatening and career ending consequences of severe rhabdomyolysis that is not quickly treated.

In addition to the instrumentation issues with the Actical accelerometers and heart rate measurement strap listed previously, this evaluation has the following limitations:

- The results from controlled fire training exercises may not be comparable to conditions experienced during actual structural firefighting activities. For example, participants were strictly timed during each live fire entry and were only involved in a single live fire training event. In an actual structural fire response fire fighters may have longer and/or multiple entries, and the structural fire conditions may differ with fuel sources (industrial chemicals, accelerants, etc.).

- Our focus group of six participants consisted of cadets who were undergoing training. The findings from this group may be limited in how they can be extrapolated to more experienced structural fire fighters as these individuals may have different opinions on the issues discussed by the group. Also, the findings from a structural fire fighter focus group may not represent opinions of wildland fire fighters of similar experience.

\section{Conclusions}

All participants were exposed to heat stress conditions that often exceeded NIOSH and ACGIH criteria, and 28 of 32 participants met our criteria for excessive heat strain. Half of the participants had above normal CK levels, and one exhibited CK elevations high enough to meet our case definition of rhabdomyolysis. This individual was diagnosed with and treated for rhabdomyolysis in the hospital.

Blood tests for hydration markers showed most participants were adequately hydrated during the training day, but some participants were not hydrating adequately between the end of one training day and the start of the next one. Discussions about firefighting as an occupation and work-related risk factors for rhabdomyolysis may not be occurring between fire fighters and their healthcare providers, especially when seeking care outside of traumatic injuries sustained during a fire response. Additionally, explicit and customized educational materials are needed to raise awareness about rhabdomyolysis within the fire service. 


\section{Recommendations}

On the basis of our findings, we recommend the actions listed below. Additional recommendations can be found in the NIOSH document, "Preventing Heat-related Illness or Death of Outdoor Workers" at http:/www.cdc.gov/niosh/docs/wp-solutions/2013-143/ pdfs/2013-143.pdf and on the OSHA website, which gives guidance on heat stress prevention in outdoor workers at https://www.osha.gov/SLTC/heatstress/.

Our recommendations are considered administrative controls, which refer to employerdictated work practices and policies to reduce or prevent hazardous exposures. Their effectiveness depends on employer commitment and employee acceptance. Regular monitoring and reinforcement are necessary to ensure that policies and procedures are followed consistently.

1. Schedule physically demanding training such as exercising or live fire training during cooler parts of the day or cooler months when temperatures and humidity are lower. Ensure incoming cadets are acclimatized before starting the training course.

2. Use a WBGT meter to monitor environmental conditions. Use the chart presented in Appendix B, Figure B1 as a general guideline to determine how long specific activities can be performed.

3. Train cadets and their instructors to recognize early signs and symptoms of rhabdomyolysis and HRI and educate them regarding the potential consequences of untreated rhabdomyolysis and HRI. Encourage cadets to inform their instructor (or supervisor once they are assigned a fire station after completion of cadet training) immediately if they develop any possible rhabdomyolysis or HRI symptoms. Inform cadets at the start of training that those who report symptoms will be allowed back into the training course once they have been medically cleared.

4. Require onsite medical staff to evaluate each participant's vital signs and mental status before and after each physically demanding training activity.

5. Encourage participants to increase fluid intake during time away from training (rest days or off-duty hours). Discourage participants from consuming drinks that contain large amounts of caffeine (totaling more than the equivalent of six cups of coffee per day), large amounts of sugar, alcohol, or creatine supplements. These may worsen dehydration and increase HRI and rhabdomyolysis risk.

6. Ensure that fire fighters have information about their risk for rhabdomyolysis and HRI that can be shared readily with medical care providers. 


\section{Appendix A: Tables}

Table A1. Heat stress and strain measurements during training activities - Day 1

\begin{tabular}{lcccccc}
\hline Activity (Participants) & $\begin{array}{c}\text { Time } \\
\text { period }\end{array}$ & $\begin{array}{c}\text { Met } \\
\text { rate* } \\
(\text { Watts) }\end{array}$ & $\begin{array}{c}\text { Max } \\
\text { WBGT } \\
\left({ }^{\circ} \mathrm{F}\right)\end{array}$ & $\begin{array}{c}\text { Range of } \\
\text { max CBTs } \\
\text { exceeding } \\
101.3\left({ }^{\circ} \mathrm{F}\right)\end{array}$ & $\begin{array}{c}\text { Number } \\
\text { with } \\
\text { max CBTs } \\
\text { exceeding } \\
101.3\left({ }^{\circ} \mathrm{F}\right)\end{array}$ & $\begin{array}{c}\text { Number } \\
\text { exceeding } \\
\text { max } \\
\text { heart rate } \\
\text { criterion† }\end{array}$ \\
\hline Physical training (22) & $0700-0745$ & 520 & 82.0 & 105.0 & 2 & 4 \\
Shower/classroom (22) & $0800-0945$ & 115 & 68.3 & None & None & None \\
$\begin{array}{l}\text { Prepare for high rise } \\
\text { training (22) }\end{array}$ & $1000-1115$ & 300 & 90.0 & None & None & None \\
High rise training (22) & $1130-1145$ & 520 & 86.4 & $102.3-103.0$ & 2 & 1 \\
Lunch (22) & $1200-1245$ & 115 & 66.8 & None & None & None \\
High rise training (22) & $1300-1415$ & 520 & 88.5 & $103.0-103.7$ & 7 & 2 \\
$\begin{array}{l}\text { Doff gear, prepare for } \\
\text { high rise training (22) }\end{array}$ & $1415-1500$ & 300 & 88.6 & None & None & None \\
High rise training (22) & $1500-1530$ & 520 & 87.4 & $103.4-104.5$ & 9 & 6 \\
$\begin{array}{l}\text { Put gear away, } \\
\text { dismissed (22) }\end{array}$ & $1530-1600$ & 300 & 87.8 & None & None & None \\
\hline
\end{tabular}

*Estimated average metabolic rate

†The maximum heart rate criterion is 180 minus the age of the participant, sustained over 3 minutes during activity. Note: some individual datasets had missing values due to loss of contact with the sensor.

Table A2. Heat stress and strain measurements during training activities - Day 2

\begin{tabular}{|c|c|c|c|c|c|c|}
\hline Activity (Participants) & $\begin{array}{l}\text { Time } \\
\text { period }\end{array}$ & $\begin{array}{c}\text { Met } \\
\text { rate* }^{*} \\
\text { (Watts) }\end{array}$ & $\begin{array}{c}\text { Max } \\
\text { WBGT } \\
\left({ }^{\circ} \mathrm{F}\right)\end{array}$ & $\begin{array}{l}\text { Range of } \\
\text { max CBTs } \\
\text { exceeding } \\
101.3\left({ }^{\circ} \mathrm{F}\right)\end{array}$ & $\begin{array}{c}\text { Number } \\
\text { with } \\
\text { max CBTs } \\
\text { exceeding } \\
101.3\left({ }^{\circ} \mathrm{F}\right)\end{array}$ & $\begin{array}{c}\text { Number } \\
\text { exceeding } \\
\text { max } \\
\text { heart rate } \\
\text { criterion† }\end{array}$ \\
\hline Physical training (22) & $0645-0715$ & 520 & 77.9 & $101.6-103.1$ & 3 & 4 \\
\hline Shower/classroom (22) & 0715-1000 & 115 & 68.8 & None & None & None \\
\hline $\begin{array}{l}\text { Prepare for high rise } \\
\text { training (22) }\end{array}$ & 1000-1015 & 300 & 82.3 & None & None & None \\
\hline High rise training (22) & $1030-1130$ & 520 & 83.1 & 101.5-102.8 & 6 & 4 \\
\hline Lunch (22) & $1145-1245$ & 115 & 68.4 & None & None & None \\
\hline $\begin{array}{l}\text { Prepare for high rise } \\
\text { training (22) }\end{array}$ & $1300-1330$ & 300 & 85.4 & None & None & None \\
\hline High rise training (22) & $1330-1445$ & 520 & 85.6 & $101.4-103.7$ & 6 & 5 \\
\hline $\begin{array}{l}\text { Put gear away, } \\
\text { dismissed (22) }\end{array}$ & 1500-1530 & 180 & 85.8 & None & None & None \\
\hline
\end{tabular}

*Estimated average metabolic rate

†The maximum heart rate criterion is 180 minus the age of the participant, sustained over 3 minutes during activity. Note: some individual datasets had missing values due to loss of contact with the sensor. 
Table A3. Heat stress and strain measurements during training activities - Day 3

\begin{tabular}{lcccccc}
\hline Activity (Participants) & $\begin{array}{c}\text { Time } \\
\text { period }\end{array}$ & $\begin{array}{c}\text { Met } \\
\text { rate* } \\
(\text { Watts) }\end{array}$ & $\begin{array}{c}\text { Max } \\
\text { WBGT } \\
\left({ }^{\circ} \mathrm{F}\right)\end{array}$ & $\begin{array}{c}\text { Range of } \\
\text { max CBTs } \\
\text { exceeding } \\
101.3\left({ }^{\circ} \mathrm{F}\right)\end{array}$ & $\begin{array}{c}\text { Number } \\
\text { with } \\
\text { max CBTs } \\
\text { exceeding } \\
101.3\left({ }^{\circ} \mathrm{F}\right)\end{array}$ & $\begin{array}{c}\text { Number } \\
\text { exceeding } \\
\text { max } \\
\text { heart rate } \\
\text { criterion† }\end{array}$ \\
\hline Classroom (22) & $0700-0730$ & 115 & 68.2 & None & None & None \\
$\begin{array}{l}\text { Prepare for live burn } \\
\text { exercise (22) }\end{array}$ & $0745-0800$ & 300 & 79.0 & None & None & None \\
Live fire entry team (4) & $0842-0915$ & 520 & $80.7 \ddagger$ & $103.7-104.8$ & 4 & 1 \\
Live fire entry team (6) & $0945-1026$ & 520 & $83.2 \ddagger$ & $103.5-105.6$ & 4 & 1 \\
Live fire entry team (4) & $1047-1111$ & 520 & $82.9 \ddagger$ & $102.2-105.1$ & 4 & 3 \\
Live fire entry team (4) & $1140-1215$ & 520 & $84.9 \ddagger$ & $102.8-107.2$ & 3 & 4 \\
Lunch (22) & $1230-1300$ & 115 & 68.1 & None & None & None \\
Live fire entry team (5) & $1350-1418$ & 520 & $84.8 \ddagger$ & $103.0-104.3$ & 2 & 4 \\
$\begin{array}{l}\text { Put gear away, } \\
\text { dismissed (22) }\end{array}$ & $1445-1500$ & 300 & 83.8 & None & None & None \\
\hline
\end{tabular}

*Estimated average metabolic rate

†The maximum heart rate criterion is 180 minus the age of the participant, sustained over 3 minutes during activity. Note: some individual datasets had missing values due to loss of contact with the sensor. ¥WBGT measurements made in the recovery area outside the burn building

Table A4. Heat stress and strain measurements during training activities - Day 4

\begin{tabular}{|c|c|c|c|c|c|c|}
\hline Activity (Participants) & $\begin{array}{l}\text { Time } \\
\text { period }\end{array}$ & $\begin{array}{c}\text { Met } \\
\text { rate* }^{*} \\
\text { (Watts) }\end{array}$ & $\begin{array}{c}\text { Max } \\
\text { WBGT } \\
\left({ }^{\circ} \mathrm{F}\right)\end{array}$ & $\begin{array}{l}\text { Range of } \\
\text { max CBTs } \\
\text { exceeding } \\
101.3\left({ }^{\circ} \mathrm{F}\right)\end{array}$ & $\begin{array}{c}\text { Number } \\
\text { with } \\
\text { max CBTs } \\
\text { exceeding } \\
101.3\left({ }^{\circ} \mathrm{F}\right) \\
\end{array}$ & $\begin{array}{c}\text { Number } \\
\text { exceeding } \\
\text { max } \\
\text { heart rate } \\
\text { criterion } \dagger\end{array}$ \\
\hline Physical training (22) & $0640-0730$ & 520 & 81.4 & 101.3-101.9 & 3 & 7 \\
\hline $\begin{array}{l}\text { Prepare for low rise } \\
\text { training (22) }\end{array}$ & $0745-0800$ & 300 & 79.8 & None & None & None \\
\hline Low rise training $(22)$ & 0830-0930 & 520 & 82.7 & None & None & None \\
\hline High rise training $(22)$ & $1000-1130$ & 520 & 87.7 & $101.3-104.4$ & 8 & 3 \\
\hline Lunch (22) & $1145-1215$ & 115 & 68.2 & None & None & None \\
\hline Low rise training (22) & $1300-1345$ & 520 & 85.6 & $103.4-104.4$ & 4 & 3 \\
\hline Classroom & $1400-1500$ & 115 & 69.8 & None & None & None \\
\hline $\begin{array}{l}\text { Put gear away, } \\
\text { dismissed (22) }\end{array}$ & $1500-1530$ & 180 & 71.0 & None & None & None \\
\hline
\end{tabular}

*Estimated average metabolic rate

†The maximum heart rate criterion is 180 minus the age of the participant, sustained over 3 minutes during activity. Note: some individual datasets had missing values due to loss of contact with the sensor. 


\section{Appendix B: Figure}

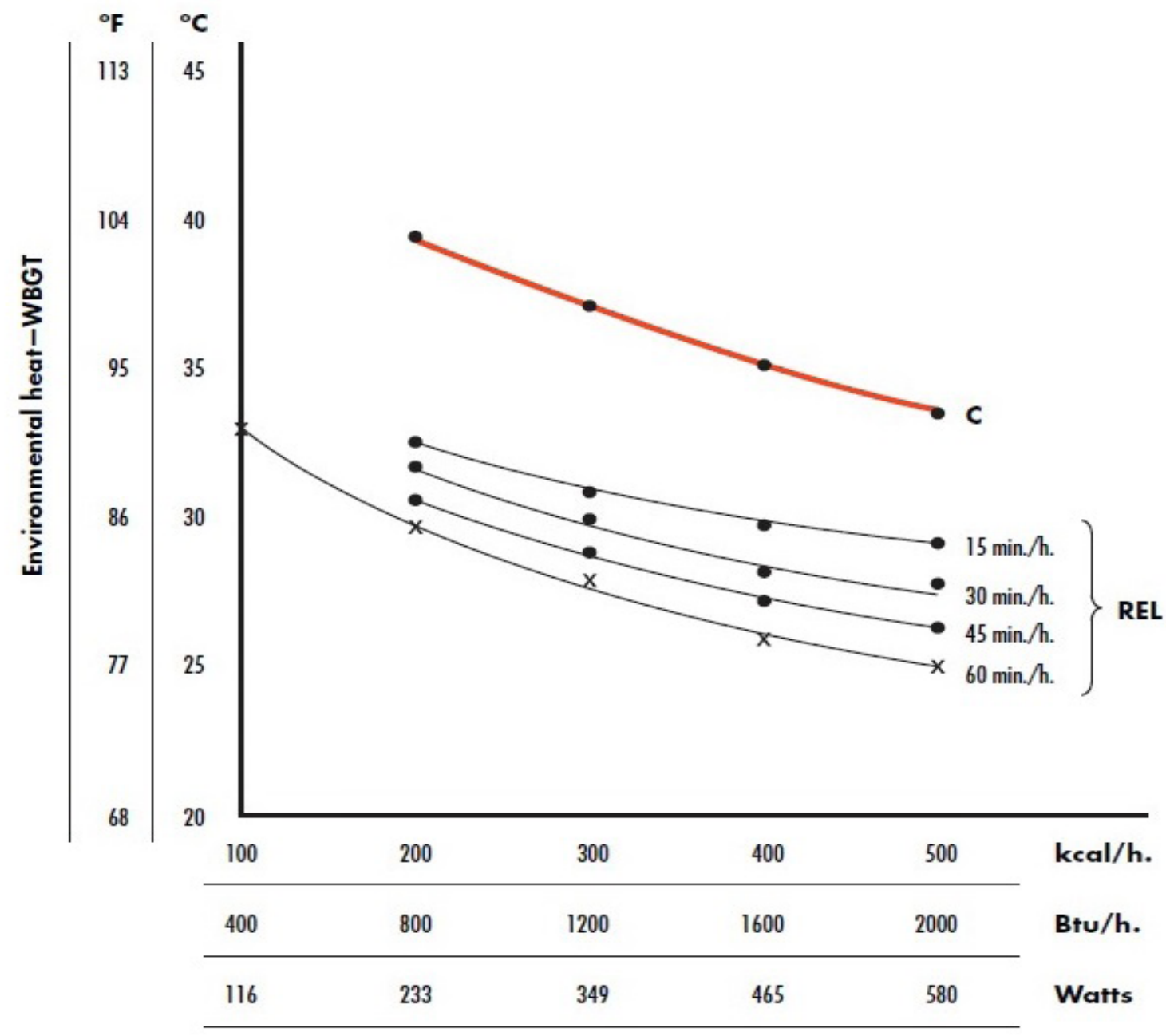

Metabolic heat

Figure B1. NIOSH-recommended heat stress exposure and ceiling limits for acclimatized workers 


\section{Appendix C: Occupational Exposure Limits and Health Effects}

\section{Heat Stress}

Many heat stress guidelines have been developed to protect people against heat-related illnesses. The objective of any heat stress index is to prevent a person's CBT from rising excessively. In 1969, the World Health Organization published a document that concluded, "it is inadvisable for CBT to exceed $100.4^{\circ} \mathrm{F}$ or for oral temperature to exceed $99.5^{\circ} \mathrm{F}$ in prolonged daily exposure to heavy work and/or heat" [WHO 1969]. Additionally, a CBT of $102.2^{\circ} \mathrm{F}$ should be considered reason to terminate exposure even when CBT is being monitored [NIOSH 1986]. This does not mean that an employee with a CBT exceeding those levels will necessarily experience adverse health effects. However, the number of unsafe acts increases as does the risk of developing heat stress illnesses [NIOSH 1986].

NIOSH recommends controlling total heat exposure so that unprotected healthy employees are not exposed to metabolic and environmental heat combinations that exceed the applicable NIOSH criteria. These criteria state that most healthy employees who work in hot environments and are exposed to combinations of environmental and metabolic heat below the NIOSH recommended action limit for unacclimatized employees or the NIOSH recommended exposure limit for acclimatized employees should be able to tolerate total heat stress without substantially increasing their risk of incurring acute adverse health effects. Also, no employee should be exposed to metabolic and environmental heat combinations that exceed applicable ceiling limits without being provided with and properly using appropriate and adequate heat-protective clothing and equipment [NIOSH 1986].

The 1986 NIOSH heat stress criteria document referenced above is being updated. A draft document released for public comment as part of a notice placed in the Federal Register in December 2013 can be viewed at http://www.gpo.gov/fdsys/pkg/FR-2013-12-27/pdf/201331066.pdf. This draft document describes five basic preventive practices that should be followed to control heat stress among employees working in hot environments:

- Limiting or modifying the duration of exposure time

- Reducing the metabolic component of the total heat load

- Enhancing the heat tolerance of the workers by heat acclimatization, physical conditioning, etc.

- Training the workers in safety and health procedures for work in hot environments

- Providing initial and periodic medical examinations to determine whether an employee can meet the total demands and physical stresses of the job with reasonable assurances the health and safety of the worker and/or fellow employees will not be placed at risk [NIOSH 2013]

The ACGIH heat stress guidelines use a decision-making process that provides step-by-step situation-dependent instructions that factor in clothing insulation values and physiological 
evaluation of heat strain [ACGIH 2015]. ACGIH WBGT screening criteria factor in the ability of the body to cool itself (clothing insulation value, humidity, and wind) and, like the NIOSH criteria, can be used to develop work/rest regimens for acclimatized and unacclimatized employees. The ACGIH WBGT-based heat exposure assessment was developed for a traditional work uniform of long-sleeved shirt and pants, and represents conditions under which it is believed that nearly all adequately hydrated, unmedicated, healthy employees may be repeatedly exposed without adverse health effects. Clothing insulation values and the appropriate WBGT adjustments, as well as descriptors of the other decision-making process components can be found in the ACGIH document "Documentation of the Threshold Limit Values for Chemical Substances and Physical Agents and Biological Exposure Indices" [ACGIH 2001]. The ACGIH TLV for heat stress provides a framework for the control of heat-related illnesses only. Although accidents and injuries can increase with increasing levels of heat stress, it is important to note that the TLVs are not directed toward controlling these outcomes [ACGIH 2015].

NIOSH and ACGIH criteria can only be used when WBGT data for the immediate work area are available and must not be used when employees wear encapsulating suits or garments that are impermeable or highly resistant to water vapor or air movement. Further assumptions regarding work demands include an 8-hour workday, 5-day workweek, two 15-minute breaks, and a 30-minute lunch break, with rest area temperatures the same as, or less than, those in work areas, and at least some air movement. While NIOSH and ACGIH guidelines distinguish between safe and dangerous levels, professional judgment must be used in administering a heat stress management program to ensure adequate protection. OSHA does not have an exposure limit for heat stress. However, the OSHA technical manual's section on heat stress refers to the ACGIH document for guidelines to evaluate employee heat stress and how to investigate the workplace [OSHA 1999].

\section{Heat Strain}

The body's response to heat stress is called heat strain. Operations involving high air temperatures, radiant heat sources, high humidity, direct physical contact with hot objects, and strenuous physical activities have a high potential for inducing heat strain in employees. Heat strain is highly individual and cannot be predicted on the basis of environmental heat stress measurements alone. Physiological monitoring for heat strain becomes necessary when impermeable clothing is worn, when heat stress screening criteria are exceeded, or when data from a detailed analysis such as the International Standards Organization required sweat rate index show excess heat stress.

ACGIH considers one indicator of physiological strain, a sustained, elevated peak heart rate, to be a useful measure of acute exposure to high-level heat stress. Sustained peak heart rate, defined by ACGIH as 180 bpm minus an individual's age over several minutes, is a leading indicator that thermal regulatory control may not be adequate and that increases in CBTs have occurred or will soon occur [ACGIH 2015]. According to ACGIH, an individual's heat stress exposure should be discontinued when any of the following heat strain indicators occur:

- Sustained (over several minutes) heart rate exceeds $180 \mathrm{bpm}$ minus the individual's age 
in years for those with normal cardiac performance

- CBT is greater than $100.4^{\circ} \mathrm{F}$ for unselected, unacclimatized personnel and greater than $101.3^{\circ} \mathrm{F}$ for medically fit, heat-acclimatized personnel

- Recovery heart rate at 1 minute after a peak work effort exceeds $110 \mathrm{bpm}$

- Presence of symptoms of sudden and severe fatigue, nausea, dizziness, lightheadedness

In addition, the ACGIH states than an individual may be at greater risk of heat strain if:

- Profuse sweating is sustained over several hours

- Weight loss over a shift is greater than $1.5 \%$ of body weight

- Twenty-four-hour urinary sodium excretion is less than 55 millimoles

\section{Acclimatization}

When employees are first exposed to a hot environment they may show signs of distress and discomfort, experience increased CBTs and heart rates, and may have headache or nausea. However, following repeated exposure, employees can adapt to the hot environment. This adaptation is called acclimatization.

Employees begin to lose acclimatization when they stop working in the heat stress conditions, and a noticeable loss occurs after 4 days. However, this loss is usually rapidly made up. Chronic illness, a short episode of mild illness (e.g., gastroenteritis), the use or misuse of pharmacologic agents, a sleep deficit, poor nutrition, or a disturbed water and electrolyte balance may reduce an employee's capacity to acclimatize [ACGIH 2015].

\section{Rhabdomyolysis}

Rhabdomyolysis is a medical condition associated with heat stress and prolonged physical exertion, resulting in the rapid breakdown of muscle which can damage the kidneys. Classic symptoms of rhabdomyolysis are muscle pain, cramping, swelling, weakness, and decreased range-of-motion of joints. One of the signs of rhabdomyolysis is dark or tea-colored urine [Brudvig and Fitzgerald 2007; Khan 2009; Cervellin et al. 2010]. However, symptoms vary between individuals, and some might not have any symptoms at all [Huerta-Alardin et al. 2005; Brudvig and Fitzgerald 2007].

Rhabdomyolysis is diagnosed by measurement of CK, also known as creatine phosphokinase, in the blood by a licensed healthcare provider. The severity of rhabdomyolysis depends upon damage to other organ systems and the peak CK level. Mild rhabdomyolysis can be treated by drinking lots of fluids [George et al. 2010]. Severe cases require hospitalization to provide fluids intravenously, monitor CK levels to guide treatment, and follow kidney function as emergent dialysis may be needed if the kidneys fail. [Bosch et al. 2009]. Inpatient monitoring would also include cardiac telemetry to look for abnormal heart rhythms induced by high potassium levels, neurological monitoring for seizures, and neurovascular monitoring for compartment syndrome. 
It is not uncommon for individuals who engage in exertional activities higher than their baseline level of fitness to develop exertional rhabdomyolysis. However, it also occurs in highly conditioned individuals who may engage in supramaximal exercise (extreme short duration anaerobic exercise) or who have other risk factors along with an exertional activity [Walsh and Page 2006].

\section{Dehydration, Volume Depletion, and Fluid Replacement}

When working in hot environments, completely replacing lost fluids as the day's work proceeds can be difficult. Sweat contains water and salt, and excessive sweating can cause dehydration, volume depletion, and electrolyte imbalances. Volume depletion is different from pure dehydration and occurs when loss of both water and salt/sodium results in a reduced circulatory blood volume [Mange et al. 1997]. Volume depletion also negates the advantage granted by high levels of aerobic fitness and heat acclimatization. Several studies have shown that volume depletion or dehydration increases CBT during exercise in temperate and hot environments. Therefore, maintaining enough water improves the body's overall function.

Drinking fluids is important to ensure adequate rehydration, and evidence shows that having drinks that taste good leads to increased consumption. Glucose-electrolyte solutions like Gatorade ${ }^{\circledR}$ can increase sodium and water absorption, and the glucose in these drinks provides energy for muscular activity [Rolls et al. 1990]. However, employees should avoid drinking large amounts of sugar-laden beverages in hot climates as this causes increased urine production that increases fluid loss through urination. Intake of caffeinated beverages and alcohol also increases urinary fluid loss and should be avoided. Because average Americans consume adequate, if not excessive, amounts of sodium in their diet, oftentimes only water replacement is needed. Oral electrolyte replacement formulas such as Gatorade can be used for moderate volume depletion or for situations involving prolonged sweating. Salt tablets are not recommended. More information on heat stress and strain is available at http://www.cdc.gov/niosh/topics/heatstress/. 


\section{Appendix D: Probes Used During Focus Groups}

A. Probe: Are you familiar with rhabdomyolysis? If so, do you believe that you are at risk for this condition because you are a structural fire fighter?

B. Probe: Does your personal physician know you are a fire fighter? If so, do you talk about your risk factors for certain conditions such as rhabdo with him or her? When you are seen by a different physician (emergency room, urgent care, physicals, doctor is unavailable) do you always tell him/her that you work as a fire fighter?

C. Probe: If so, how easy is it to talk with your healthcare provider about your job and how it can affect your health? If you don't tell healthcare providers about your occupation, why don't you?

D. Probe: What sorts of items do you think would aid you in talking to healthcare providers about your occupation, and what conditions they should watch for due to the risks associated with this profession?

E. Probe: We have drafted this wallet card that identifies you as a fire fighter. There is room on the back for you to fill in your personal information. Would you carry this with you? If not, why? If so, what types of information would be useful to include on this card to alert healthcare providers to the risk associated with your job, specifically that they should have a lower threshold to test you for rhabdo? 


\section{References}

Abaxis [2011]. Piccolo® Metlyte 8 reagent disc package insert. Union City, CA: Abaxis, Inc. [http:/www.piccoloxpress.com/wp-content/uploads/400-7122-1RevMMetLyte8ReagentDiscPIEnglish.pdf]. Date accessed: September 2015 as February 2014 update.

ACGIH [2001]. Heat stress. In: Documentation of the threshold limit values for physical agents. 7th ed. Cincinnati, OH: American Conference of Governmental Industrial Hygienists.

ACGIH [2015]. 2015 TLVs ${ }^{\circledR}$ and BEIs ${ }^{\circledR}$ : threshold limit values for chemical substances and physical agents and biological exposure indices. Cincinnati, $\mathrm{OH}$ : American Conference of Governmental Industrial Hygienists.

Bontempo LJ, Kaji AH [2010]. Rhabdomyolysis. In: Marx JA, ed. Rosen's emergency medicine: concepts and clinical practice. 7th ed. Philadelphia, PA: Mosby Elsevier Publishers, pp. 2250-2257.

Bosch X, Poch E, Grau JM [2009]. Rhabdomyolysis and acute kidney injury. NEJM 361(1):62-72.

Brudvig TJ, Fitzgerald PI [2007]. Identification of signs and symptoms of acute exertional rhabdomyolysis in athletes: a guide for the practitioner. Strength Cond J 29(1):10-14.

Byrne C, Lim CL [2007]. The ingestible telemetric body core temperature sensor: a review of validity and exercise applications. Br J Sports Med 41(3):126-133.

CDC (Centers for Disease Control and Prevention) [1998]. Guideline for infection control in health care personnel. Am J Infection Control 26(3):289-354.

Cervellin G, Comelli I, Lippi G [2010]. Rhabdomyolysis: historical background, clinical, diagnostic and therapeutic features. Clin Chem Lab Med 48(6):749-756.

CFR. Code of Federal Regulations. Washington, DC: U.S. Government Printing Office, Office of the Federal Register.

Department of the Army and Air Force [2003]. Technical bulletin: heat stress control and heat casualty management. Technical Bulletin Medical 507. Washington, DC: Headquarters of the Department of the Army and Air Force.

Gabow PA, Kaehny WD, Kelleher SP [1982]. The spectrum of rhabdomyolysis. Medicine 61(3):141-152.

George M, Delgaudio A, Salhanick SD [2010]. Exertional rhabdomyolysis-when should we start worrying? Ped Emerg Care 26(11):864-866.

Huerta-Alardin A, Varon J, Marik PE [2005]. Bench-to-bedside review: rhabdomyolysis - an overview for clinicians. Critical Care 9(2):158-229. 
Kelen GD, Hsu E [2011]. Chapter 21. Fluids and electrolytes. In: Tintinalli JE, Stapczynski JS, Ma OJ, Cline DM, Cydulka RK, Meckler GD, eds. Tintinalli's Emergency Medicine: A Comprehensive Study Guide, 7th Edition. New York, NY: McGraw-Hill. [http:// accessmedicine. $\mathrm{mhmedical}$.com/content.aspx?bookid=348\&Sectionid=40381482]. Date accessed: September 2015.

Khan FY [2009]. Rhabdomyolysis: a review of the literature. Netherlands J Med 67(9):272-283.

Mange K, Matsuura D, Cizman B, Soto H, Ziyadeh FN, Goldfard S, Neilson EG [1997]. Language guiding therapy: the case of dehydration versus volume depletion. Ann Intern Med 127(9):848-853.

McKenzie JE, Osgood DW [2004]. Validation of a new telemetric core temperature monitor. J Therm Biol 29(7):605-611.

Morgan DL [1998]. The focus group kit: the focus group guidebook. Thousand Oaks, CA: SAGE Publications, Inc, pp. 9-16.

NIOSH [1986]. NIOSH criteria for a recommended standard: occupational exposure to hot environments. Cincinnati, OH: U.S. Department of Health and Human Services, Centers for Disease Control and Prevention, National Institute for Occupational Safety and Health, DHHS (NIOSH) Publication No. 86-113. [http://www.cdc.gov/niosh/docs/86-113/86-113. pdf]. Date accessed: September 2015.

NIOSH [2011]. Health hazard evaluation letter report of April 25, 2011. By McFadden J and Eisenberg J. Cincinnati, OH: U.S. Department of Health and Human Services, Centers for Disease Control and Prevention, National Institute for Occupational Safety and Health, NIOSH HHE No. 2011-0039.

NIOSH [2013]. NIOSH criteria for a recommended standard: occupational exposure to hot environments. External review draft released for public comment. Cincinnati, OH: U.S. Department of Health and Human Services, Centers for Disease Control and Prevention, National Institute for Occupational Safety and Health.

O’Connor FG, Duester PA [2011]. Rhabdomyolysis. In: Goldman L, Schafer AI, eds. Goldman's Cecil medicine, 24th ed. New York: Elsevier Saunders Publishers, pp. 700-705.

OSHA [1999]. OSHA Technical Manual, Section III, Chapter 4, Heat stress. [http://www. osha.gov/dts/osta/otm/otm_iii/otm_iii_4.html]. Date accessed: September 2015.

Rolls BJ, Kim S, Federoff IC [1990]. Effects of drinks sweetened with sucrose or aspartame on hunger, thirst and food intake in men. Physiol Behav 48(1):19-26.

Sawka MN, Pandolf KB [2001]. Physical exercise in hot climates: physiology, performance, and biomedical issues. In: Medical aspects of harsh environments. Washington, DC: Office of the Surgeon General at Textbooks of Military Medicine Publications. Vol 1, pp. 89-90.

Singer GS, Brenner BM [2008]. Fluid and electrolyte disturbances. In: Harrison's principles of internal medicine. 17th ed. New York: McGraw Hill Publishers, pp. 275-276. 
Walsh JJ, Page SM [2006]. Rhabdomyolysis and compartment syndrome in military trainees. In BL DeKoning, Recruit Medicine (pp. 165-174). Falls Church, VA: Department of Defense, Office of the Surgeon General, U.S. Army, Borden Institute.

WHO [1969]. Technical Report Series 412: health factors involved in working under conditions of heat stress. Geneva, Switzerland. 
Keywords: North American Industry Classification System 611519 (Fire fighter Training Schools), Texas, fire fighters, heat stress, heat strain, rhabdomyolysis, creatine kinase, wet bulb globe temperature, WBGT, core body temperature, heart rate, dehydration 
The Health Hazard Evaluation Program investigates possible health hazards in the workplace under the authority of the Occupational Safety and Health Act of 1970 (29 U.S.C. § 669(a) (6)). The Health Hazard Evaluation Program also provides, upon request, technical assistance to federal, state, and local agencies to investigate occupational health hazards and to prevent occupational disease or injury. Regulations guiding the Program can be found in Title 42, Code of Federal Regulations, Part 85; Requests for Health Hazard Evaluations (42 CFR Part 85).

\section{Disclaimer}

The recommendations in this report are made on the basis of the findings at the workplace evaluated and may not be applicable to other workplaces.

Mention of any company or product in this report does not constitute endorsement by NIOSH.

Citations to Web sites external to NIOSH do not constitute NIOSH endorsement of the sponsoring organizations or their programs or products. NIOSH is not responsible for the content of these Web sites. All Web addresses referenced in this document were accessible as of the publication date.

\section{Acknowledgments}

Desktop Publisher: Shawna Watts

Editor: Ellen Galloway

Health Communications Specialist (Focus Group): Stefanie Brown

Industrial Hygiene Field Assistance: Kevin L. Dunn, Bradley King

Logistics: Donnie Booher

Medical Field Assistance: Deborah Sammons, Shirley Robertson, Donnie Booher, and John Clark

\section{Availability of Report}

Copies of this report have been sent to the employer, employees, and union at the facility. The state and local health department and the Occupational Safety and Health Administration Regional Office have also received a copy. This report is not copyrighted and may be freely reproduced.

This report is available at http://www.cdc.gov/niosh/hhe/reports/pdfs/2012-0039-3242.pdf.

\section{Recommended citation for this report:}

NIOSH [2015]. Evaluation of heat stress, heat strain, and rhabdomyolysis during structural fire fighter training. By Eisenberg J, Methner M, Dowell CH, Mueller C. Cincinnati, OH: U.S. Department of Health and Human Services, Centers for Disease Control and Prevention, National Institute for Occupational Safety and Health, NIOSH HHE Report No. 2012-0039-3242. 
Delivering on the Nation's promise:

Safety and health at work for all people through research and prevention

To receive NIOSH documents or more information about occupational safety and health topics, please contact NIOSH:

Telephone: 1-800-CDC-INFO (1-800-232-4636)

TTY: 1-888-232-6348

CDC INFO: www.cdc.gov/info

or visit the NIOSH Web site at www.cdc.gov/niosh

For a monthly update on news at $\mathrm{NIOSH}$, subscribe to

$\mathrm{NIOSH}$ eNews by visiting www.cdc.gov/niosh/eNews. 